
\title{
R Reserarch Suare \\ Removal of Organic Pollutantsfrom Produced Water by Batch Adsorption Treatment
}

\section{Eman Hashim Khader}

Institute of Chemical Technology Department of Chemical Engineering

Thamer Jassim Mohammed

Institute of Chemical Technology Department of Chemical Engineering

Nourollah Mirghaffari

Natural Resources Institute

ali Dawood Salman ( $\nabla$ ali.dawood@mk.uni-pannon.hu )

Environmental https://orcid.org/0000-0002-5842-3773

\section{Tatjána Juzsakova}

Environmental engineering

Thamer Adnan Abdullah

Environmental engineering

\section{Research Article}

Keywords: Activated carbon, Adsorption, Chemical oxygen demand, Oil, Produced water, Zeolites

Posted Date: February 23rd, 2021

DOl: https://doi.org/10.21203/rs.3.rs-214883/v1

License: (c) (i) This work is licensed under a Creative Commons Attribution 4.0 International License.

Read Full License 


\title{
Highlights:
}

- A suitable and economic adsorption technique has been applied for removal of organic pollutants from produced oilfield water.

- Different types of adsorbents (powdered activated carbon, clinoptilolite natural zeolite and synthetic zeolite type X) and comparison between them to determine which one is the best adsorbent for the organic pollutant.

- $\quad$ Regeneration of the consumed adsorbents was studied to find out the possibility of reusing the adsorbents.

\begin{abstract}
This paper investigates the adsorption of oil, chemical oxygen demand (COD) and turbidity of the produced water (PW) which accompanies the oil exploration and production after treatment by using powdered activated carbon (PAC), clinoptilolite natural zeolite (CNZ) and synthetic zeolite type X (XSZ). Moreover, the paper deals with the comparison of pollutant removal over different adsorbents. Sorption was carried out in batch sorption system. The operating factors including adsorbent dosage, time, $\mathrm{pH}$, oil concentration and temperature were investigated to determine the optimum operational conditions. Three adsorption isotherm models (Langmuir, Freundlich and Temkin models) were applied. The kinetics of the oil sorption and the change in COD content over on PAC and CNZ were studied by using pseudo-first order and pseudo-second order kinetics models. Maximum oil removal efficiencies (99.57, 95.87 and 99.84\%), COD and total petroleum hydrocarbon (TPH), respectively were found at PAC adsorbent dose of $0.25 \mathrm{~g} / 100 \mathrm{~mL}$. However, maximum turbidity removal efficiency (99.97\%) was obtained when zeolite $\mathrm{X}$ was used at $0.25 \mathrm{~g} / 100 \mathrm{~mL}$ concentration. It is not very different from that obtained over PAC (99.65\%). The results proved that adsorption over PAC is most effective compared to zeolites in the removal of organic pollutants from PW. Also, regeneration of the consumed adsorbents was carried out in this work to find out the possibility of reusing the adsorbents. The consumed powdered activated carbon and zeolites can be effectively regenerated and reused by chemical treatment and thermal treatment respectively.
\end{abstract}

Keywords: Activated carbon, Adsorption, Chemical oxygen demand, Oil, Produced water, Zeolites.

$\begin{array}{ll}\text { Abbreviations } & \\ \text { CNZ } & \text { Clinoptilolite natural zeolite } \\ \text { COD } & \text { Chemical oxygen demand } \\ \text { PAC } & \text { Powdered activated carbon } \\ \text { PW } & \text { Produced water } \\ \text { TDS } & \text { Total dissolved solid } \\ \text { TPH } & \text { Total petroleum hydrocarbon } \\ \text { WHO } & \text { Word Health Organization } \\ \text { XSZ } & \text { Synthetic zeolite type X }\end{array}$

\section{Introduction}

Produced water (PW) is the largest stream of wastewater generated by the petroleum industry during oil and gas fields exploration and production and contains a wide range of hydrocarbons in free, dispersed, and dissolved forms (Al-Ghouti et al. 2019). Produced water has a complex composition, but its constituents can be broadly classified into organic and inorganic compounds, including dissolved and dispersed oils, grease, heavy metals, radionuclides, treating chemicals, formation solids, salts, dissolved gases, scale products, waxes, microorganisms and dissolved oxygen (Igunnu and Chen 2014). Globally, 250 million barrels of water are produced daily from both oil and gas fields, and more than $40 \%$ of this is discharged into the environment (Hedar 2018), the discharge of PW may lead to severe pollution of surface, soil and underground water, the hazard comes from the absence of appropriate treatment. Therefore, several technologies are applied for PW treatment (Show 2021) and can be divided into biological, chemical, or physical methods (Fakhru'l-Razi 2009; Sen 2015). Microbial 
degradation (Quintana et al. 2005), filtration (Guo et al. 2018), chemical oxidation (Zhu et al. 2020), electrochemical oxidation (Nidheesh et al. 2020), coagulation (Khader et al. 2018), and membrane separation (Xiao et al. 2010) may be suitable technologies for the elimination of environmental pollution. However, these techniques have their own limitations such as high cost, generation of secondary pollutants, and poor removal efficiency (Gupta et al. 2012; Han 2007). Adsorption is one of the most important conventional techniques and it is considered a means of produced water purification and reclamation (Zhao 2015) (removal of organics, inorganic and biological contaminants that are soluble and insoluble in water) to meet the environmental standards at minimal cost (Rashed 2013), so has been introduced as an environmental-friendly and cost-effective and economic method It can replace others conventional methods for the treatment of pollutants in the wastewater (Kim et al. 2018; Albayati et al. 2020). Due to the fact that it can be used in a wide range of applications and has a removal efficiency reaching up to $99 \%$, ease of separation of the targeted compounds from the dilute solution, simplicity of design and operation, insensitive to toxic materials, and the possibility of recovery the adsorbed materials easily by different methods (desorbing agents, leaching by means of chemical reagents, biological processes, and thermal treatment) (Pirilä 2015; Alardhi et al. 2020).

In the adsorption process, several types of adsorbents such as activated carbons, zeolites, activated alumina, or low-cost materials ( limestone, rice husk ash, peat, etc.) can be used. Activated carbon is considered the most widely used adsorbent (Babel and Kurniawan 2003). Activated carbon is an amorphous, microcrystalline, and non-graphic solid which has some properties such as high thermal stability, high stability against light, porous and solid structure, high mechanical stability, high ratio of surface to volume, and achieving high purity. Also, since activated carbon has a high ability for adsorption of different species, it can be an appropriate adsorbent for the removal of ions and organic pollutants from wastewater (Jhadhav 2015).

Zeolites are one of the most universally used adsorbents in water treatment owing to their cost-effectiveness(Pandey et al. 2020). Zeolites are mineral-crystalline aluminosilicate and hydrated alkali and alkaline earth metals with a tridimensional lattice which are divided into two categories of natural zeolites (clinoptilolite, analcime, limonite, phillipsite, mordenite) and artificial zeolites (Malekmohammadi et al. 2016). Clinoptilolite is probably the most abundant among more than 40 natural zeolite species, the low cost, relatively high specific surface area, and high ion-exchange capacity of clinoptilolite make it attractive for water and wastewater treatment (Hamidpour et al. 2010; Yang et al. 2011). The synthetic zeolites are usually obtained from the chemical reaction between sodium silicate, $\mathrm{Na}_{2} \mathrm{SiO}_{3}$, and sodium aluminate, $\mathrm{NaAlO}_{2}$, under varying conditions of temperature, pressure, and reaction time. In addition to pure chemical reagents, raw materials such as fly ash, perlite, clay minerals, and obsidian can be used for the synthesis of zeolites (Bandura et al. 2017).

Some researchers studied the ability the activated carbon and zeolites (natural and synthetic) in the treatment of pollutants from wastewater. Pandey et al. 2020 applied the clinoptilolite zeolite, molybdenum sulphide $\left(\mathrm{MoS}_{2}\right)$, and $\mathrm{MoS}_{2}$-clinoptilolite composite to treat lead $(\mathrm{Pb})$ in industrial mining wastewater. Al-Haddad et al. 2007 used the natural zeolite (clinoptilolite), manufactured synthetic zeolite and activated carbon to treat ammonia from refinery wastewater. Payne and Abdel-Fattah 2004 compared and evaluates the performance of activated carbon and natural zeolites (clinoptilolite and chabazite) and synthetic zeolites (Faujasite (13X) and Linde type A (5A) in the treatment of Pb2+ by using batch adsorption. Bandura et al. 2016 utilized synthetic zeolites (Na-P1 and Na-X) and natural zeolites (clinoptilolite and diatomite) to reduce (Benzene, Toluene, Xylene) BTX from gas streams. Malekmohammadi et al. 2016 studied the efficiency of adsorbents (zeolite, silica and activated carbon) in the treatment of pollutants (COD, phosphate, iron, ammonium and turbidity). Vega et al. 2018 applied the faujasite zeolite type $\mathrm{X}$ to remove heavy metals, water hardness, ammoniacal nitrogen and COD. Daoud 2020 evaluated the ability mixture of natural Zeolite and Granular Activated Carbon in treatment of $\mathrm{Fe}, \mathrm{Cu}, \mathrm{Zn}$, and $\mathrm{Pb}$ from Landfill Leachatecontaminated Groundwater. Paliulis 2016 tested the chemically modified and natural zeolite consisting of mordenite and clinoptilolite minerals in reduce of formaldehyde by the adsorption process. El-Naas et al. 2010 evaluated the performance of locally prepared date-pit activated carbon for the removal of COD from petroleum refinery wastewater. Malik 2004 used the mahogany sawdust to develop carbon adsorbent for the reduction of direct dyes from textile wastewater. Nekoo and Fatemi 2013 employed Granular activated carbon for the removal of COD. However, there is no researcher appearing the simultaneous treatment of oil content, COD, TPH contents, and turbidity in produced water by unmodified activated carbon and zeolites (natural and synthetic).

The aim of this study to investigate the ability of several adsorbents (activated carbon, natural zeolites, and synthetic zeolite type $\mathrm{X}$ ) and comparison between them in the treatment of produced water ( removal of oil content, COD, TPH contents, and turbidity). The removal of these components is necessary in order to meet the requirements stipulated by the World Health Organization (WHO) and the Specifications of the Iraqi Central Organization for Standardization and Quality 
Control. In addition, the adsorption kinetics, isotherm behaviors were studies and the thermodynamic parameters were calculated as well.

\section{Materials and methods \\ Materials}

Natural zeolite (clinoptilolite) was used in this study obtained from Atcholding Company Iran and synthetic zeolite type X and powdered activated carbon were purchased from Sigma-Aldrich Company . Prior to the experiment, the zeolites were washed with distilled water and dried in an oven at $110^{\circ} \mathrm{C}$ for $24 \mathrm{~h}$. Sodium hydroxide [NaOH, Purity $\geq 97 \%$ ]. Hydrochloric acid ( $\mathrm{HCl}$, Purity $\geq 98 \%$ )] obtained from Sigma-Aldrich Company. The crude oil (light oil) and clay (bentonite) were supplied from the Petroleum Research and Development Center in the Oil Ministry of Iraq. The chemical composition was determined by X-ray Fluorescence method. The surface area of the sorbents was determined by the Brunauer-Emmet-Teller method. The values of other properties were determined as well and the results are summarized in Table 1.

Table 1 Properties and chemical composition of adsorbents (PAC, CNZ and XSZ)

\begin{tabular}{lcccccc}
\hline Properties & PAC & CNZ & XSZ & \multicolumn{3}{c}{ Composition (wt } \\
\hline & & & & $\mathrm{Na}_{2} \mathrm{O}$ & $\mathrm{CNZ}$ & $\mathrm{XSZ}$ \\
Surface area $\left(\mathrm{m}^{2} / \mathrm{g}\right)$ & 853.8 & 76.35 & 316.80 & $\mathrm{MgO}$ & 1.86 & 5.38 \\
Pore volume $\left(\mathrm{mL}^{3} / \mathrm{g}\right)$ & 0.799 & 0.251 & 0.543 & $\mathrm{Al}_{2} \mathrm{O}_{3}$ & 0.71 & 2.64 \\
Pore diameter(nm) & 3.74 & 7.50 & 3.61 & $\mathrm{SiO}_{2}$ & 12.84 & 26.75 \\
Real density $\left(\mathrm{g} / \mathrm{mL}^{3}\right)$ & 0.423 & 2.430 & 1.242 & $\mathrm{~K}_{2} \mathrm{O}$ & 52.32 & 32.24 \\
& & & & $\mathrm{CaO}_{2}$ & 2.46 & 0.54 \\
& & & & $\mathrm{TiO}_{2}$ & 0.25 & 8.78 \\
& & & & $\mathrm{MnO}_{2}$ & 0.06 & 1.65 \\
& & & & $\mathrm{Fe}_{2} \mathrm{O}_{3}$ & 0.03 & 0.14 \\
& & & & $\mathrm{P}_{2} \mathrm{O}_{5}$ & 1.49 & 7.01 \\
& & & & loss of & 0.07 & 0.37 \\
& & & & ignition & 6.84 & 14.95 \\
\hline
\end{tabular}

\section{Synthetic produced water}

Chemicals were added to $1000 \mathrm{~mL}$ distilled water, such as clay materials (bentonite : $4 \mathrm{~g}$ ), crude oil (light oil : $0.1 \mathrm{~g}$ ) and salt $(\mathrm{NaCl}: 100 \mathrm{~g})$ to prepare the synthetic produced water in order to adjust the properties of the PW for this research. The value of oil and turbidity of the synthetic PW was set to become equivalent to the parameters (oil content, turbidity and salt content) of the natural PW which was taken from the Southern Oil Company in Basra, Iraq. The crude oil and clay materials were added to the distilled water and then the suspension was stirred for about $15 \mathrm{~min}$ at $27000 \mathrm{rpm}$ to get a uniform diffusion of clay particles and oil droplets. Table 2 summarizes the characteristics of the synthetic produced water used in this study.

Table 2 Characteristics of the synthetic produced water

\begin{tabular}{lc}
\hline Parameter & Range \\
\hline Oil \& grease (ppm) & $50-10000$ \\
COD (ppm) & $1357-28609$ \\
Turbidity (NTU) & 435 \\
TDS (ppm) & 100000 \\
pH & $2-10$ \\
\hline
\end{tabular}

\section{Batch adsorption methods}

The batch adsorption experiments were carried out in $150 \mathrm{ml}$ conical glass flask containing $100 \mathrm{ml}$ of produced water and $0.03-0.3 \mathrm{~g}$ adsorbents were added to the water. The flask was placed onto a mechanical shaker device (Water Bath Shaker Heidolph Unimax 1010 model) used to mix the PW with adsorbents, set under constant stirring rate (200 rpm). In order to follow up the remaining pollutant concentrations, the samples withdrawn by pipette were centrifuged at $4500 \mathrm{rpm}$ for $10 \mathrm{~min}$. Then, the adsorbent was separated from the sorbate. Figure 1 shows a schematic view of an experimental apparatus including the shaker water bath model (WisdBath) and centrifuge. 


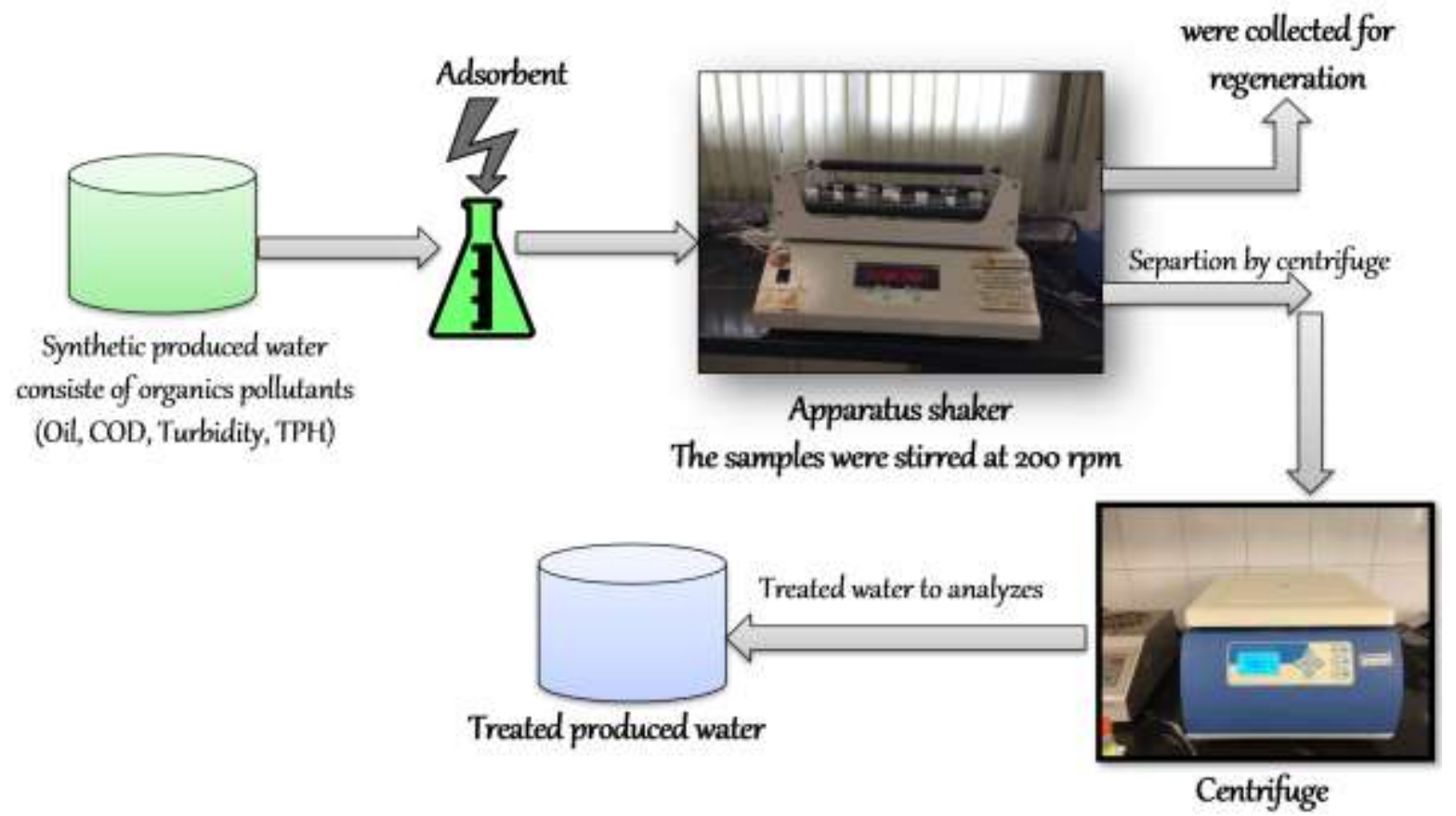

Fig. 1 schematic view of an experimental apparatus

The pollutants remaining in the treated water were analyzed by using special analytical instruments for each pollutants using (Oil Content Analyzer) HORIBA instrument model OCMA-350 to measure oil content in PW, The turbidity meter that used in the measurements of the samples turbidities during the experiments was Lovibond Turb Direct model/serial number12/1805 with a measurement unit NTU (Nephlometric turbidity unit), COD was measured by using COD instrument model Lovibond SN11/25370. Adsorption time ranged from 10 to $90 \mathrm{~min}$ and $\mathrm{pH}$ range was 2-10. $\mathrm{pH}$ meter used in this work allows measuring pH, EC (conductivity) and TDS ( model MW801) Adsorption isotherms were plotted by using different initial oil concentrations $\left(\mathrm{C}_{\mathrm{o}}=50-1000 \mathrm{ppm}\right)$ and $\operatorname{COD}\left(\mathrm{C}_{\mathrm{o}}=1357-26890 \mathrm{ppm}\right)$ at $25{ }^{\circ} \mathrm{C}$. Thermodynamic adsorption experiments were conducted over a temperature range $\left(10\right.$ to $\left.55^{\circ} \mathrm{C}\right)$. The percentage of removal efficiency and the amount of pollutant adsorbed by the adsorbents were calculated by the following equations:

$$
\begin{array}{r}
\text { Removal \%= } \frac{(\mathrm{Co}-\mathrm{Ce})}{C o} * 100 \\
\mathrm{q}_{\mathrm{e}}=\frac{(\mathrm{Co}-\mathrm{Ce}) * \mathrm{~V}}{m}
\end{array}
$$

where: $C_{o}$ and $C_{e}$ are the initial and equilibrium concentrations of pollutants in PW, respectively; $q_{e}$ is the amount of pollutant adsorbed at equilibrium, $\mathrm{V}$ is the solution volume and $\mathrm{m}$ is the mass of the adsorbents used.

\section{Results and discussion}

The effects of adsorbents dose on the oil, COD removal efficiencies and decrease of turbidity are illustrated in Figure 2. As shown, the removal efficiency increases with an increase in the amount of adsorbent up to $0.25 \mathrm{~g}$. This can be explained by the introduction of more binding/sorption sites and larger specific surface area. However, further increase in the dose of adsorbent $(>0.25 \mathrm{~g}$ ) doesn't result in additional removal, it remains almost constant or decreasing, which could be attributed to saturation of the binding sites (Mohan and Gandhimathi 2008). The initial oil and COD concentrations of the PW were 100 ppm and $2508 \mathrm{ppm}$ respectively. Based on the experiments carried out with dosage addition it was determined that by using 0.03-0.3 g/100 mL PAC and CNZ at $\mathrm{pH}=7$, and at time of $30 \mathrm{~min}$, it is capable of adsorbing up to $87.2 \%$ of the initial oil 
content, and $79.1 \%$ of initial COD content and $98.15 \%$ of the initial turbidity (at $0.3 \mathrm{~g} \mathrm{PAC}$ dose $/ 100 \mathrm{~mL}$ ). Whereas at 0.3 $\mathrm{g}$ CNZ dose $/ 100 \mathrm{~mL}$ addition the removal efficiency reached up to $74.6 \%$ for the oil, $49.92 \%$ for the COD and $98.85 \%$ for the turbidity.
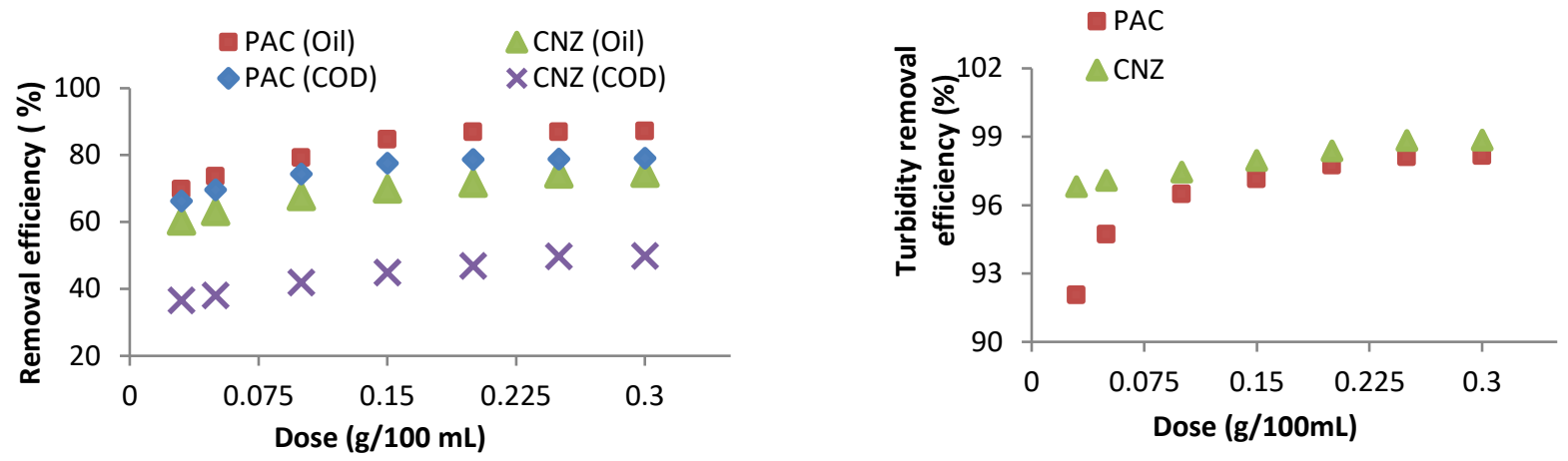

Fig. 2 (A) Effect of adsorbent dose on oil and COD removal efficiency $\left(\mathrm{C}_{\mathrm{o}}\right.$ Oil $=100 \mathrm{ppm}, \mathrm{C}_{\mathrm{o}} \mathrm{COD}=2508 \mathrm{ppm}, \mathrm{pH}=7$, time $\left.=30 \mathrm{~min}\right)(\mathbf{B}) \mathrm{Effect}$ of adsorbent dose on the removal efficiency of turbidity (Cinitial turbidity $=435 \mathrm{NTU}, \mathrm{pH}=7$, time $=30 \mathrm{~min}$ )

The adsorption of oil, COD and turbidity over PAC and CNZ was investigated in the function of time at 100 ppm initial oil concentration and 1357 ppm initial COD concentration, and the results are depicted in Figure 3.
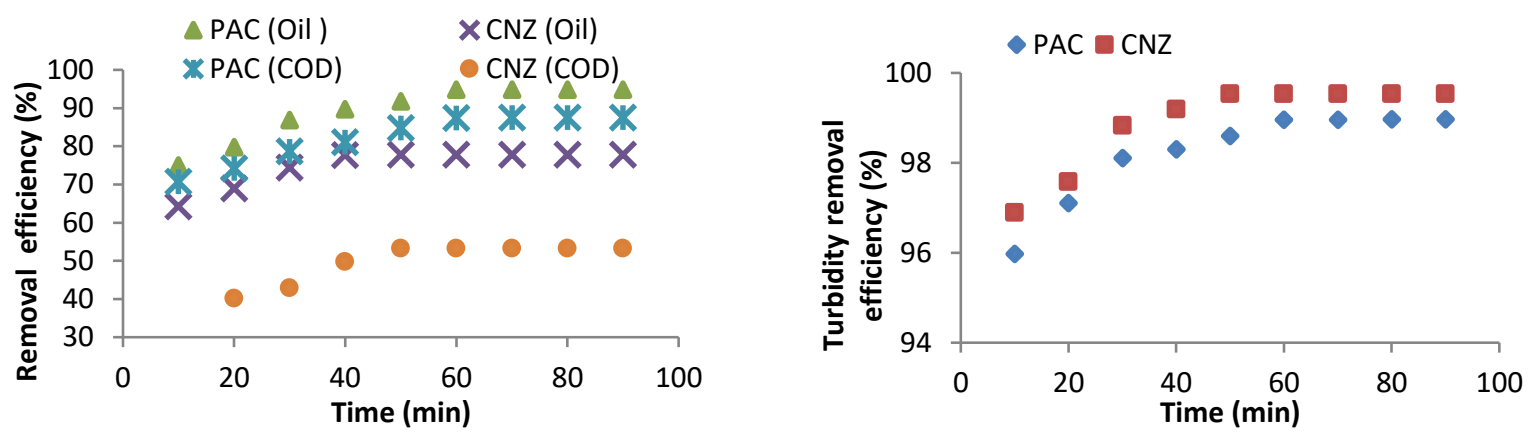

Fig. 3 (A) Effect of contact time on oil and COD removal efficiency $\left(\mathrm{C}_{\mathrm{o}}\right.$ Oil $\left.=100 \mathrm{ppm}, \mathrm{C}_{\mathrm{o}} \mathrm{COD}=2508 \mathrm{ppm}, \mathrm{pH}=7, \mathrm{dose}=0.3 \mathrm{~g} / 100 \mathrm{~mL}\right)(\mathbf{B})$ Effect of adsorbent dose on the removal efficiency of turbidity (Cinitial turbidity $=435 \mathrm{NTU}, \mathrm{pH}=7$, dose $=0.3 \mathrm{~g} / 100 \mathrm{~mL}$ )

It can be seen in Figure 3 that the removal percentage showed an increasing trend with time and the adsorption consisted of two significant phases; the primary rapid uptake phase was followed by a relatively slow uptake phase before the equilibrium was reached. This is due to a large number of vacant surface sites available for adsorption and as the contact time increased, less adsorption sites on the adsorbent surfaces were available and were difficult to be occupied due to the repulsive forces between the oil molecules on the adsorbents. The adsorption reached the equilibrium within approximately $60 \mathrm{~min}$ and $50 \mathrm{~min}$ when PAC and CNZ adsorbents were used with oil removal efficiencies reaching up to $94.8 \%$ and $77.7 \%$ for PAC and CNZ, respectively. The COD removal efficiencies reached up to $87.4 \%$ and $53.18 \%$ for PAC and CNZ, respectively, while the turbidity removal efficiencies reached up to $98.96 \%$ for PAC and $99.53 \%$ for CNZ.

The $\mathrm{pH}$ plays a vital role in the removal of oil, COD and turbidity over PAC and CNZ adsorbents. It has an effect on the surface properties and binding sites present on the surface of the adsorbents (Ibrahim et al. 2009) . In this experiment, optimal adsorbent dose was mixed with $100 \mathrm{~mL}$ of $\mathrm{PW}$ at $\mathrm{pH}$ values that ranged from 2 to 10 . The optimal times of 50 and $60 \mathrm{~min}$ were set during the experiments. The desired $\mathrm{pH}$ values of $\mathrm{PW}$ were obtained using $0.1 \mathrm{~N} \mathrm{HCl}$ and $0.1 \mathrm{~N} \mathrm{NaOH}$. In Figure 4 it can be seen that the removal efficiency increases as the $\mathrm{pH}$ decreased. The maximum oil removal was $97.85 \%$ and $83.9 \%$, the COD removal was $93.78 \%$ and $60.12 \%$ and the turbidity removal was $99.48 \%$ and $99.8 \%$ at $\mathrm{pH}=2$ for $\mathrm{PAC}$ and CNZ adsorbents, respectively. The high efficiencies at low $\mathrm{pH}$ can be attributed to the electrostatic attractions between the protonated binding sites on the surface of adsorbents and oil, COD constituents and molecules resulting in turbidity. This results in high removal efficiency at $\mathrm{pH}=2$ ( Chiou and $\mathrm{Li} 2003$ ). 

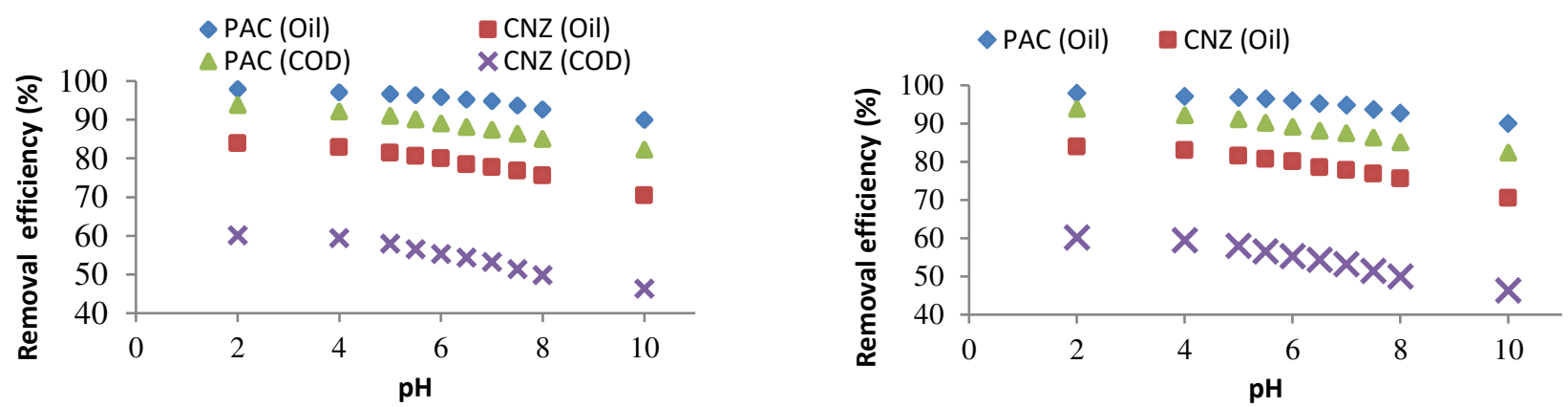

Fig. 4 (A) Effect of contact time on oil and COD removal efficiency $\left(\mathrm{C}_{\mathrm{o}}\right.$ oil $=100 \mathrm{ppm}, \mathrm{C}_{\mathrm{o}} \mathrm{COD}=2508 \mathrm{ppm}, \mathrm{pH}=7$, dose $=0.3 \mathrm{~g} / 100 \mathrm{~mL}$, time $=60 \mathrm{~min} \& 50 \mathrm{~min})(\mathbf{B})$ Effect of adsorbent dose on the removal efficiency of turbidity (Cinitial turbidity $=435 \mathrm{NTU}, \mathrm{pH}=7$, dose $=0.3 \mathrm{~g} / 100 \mathrm{~mL}$, time $=60 \mathrm{~min})$

The effects of initial oil concentrations $\left(\mathrm{C}_{\mathrm{o}}=50-1000 \mathrm{ppm}\right)$ and COD concentrations $\left(\mathrm{C}_{\mathrm{o}}=1357-26890 \mathrm{ppm}\right)$ on the oil and COD removal efficiencies and turbidity decreasing capacity of PAC and CNZ adsorbents were studied at the equilibrium time. It can be observed from Figure 5 that the oil removal percentage decreased from 99.58\% to 80.43\% over PAC and from $84.8 \%$ to $71.02 \%$ over CNZ. The COD removal decreased from $95.87 \%$ to $67.15 \%$ over PAC and from $63.74 \%$ to $29.02 \%$ over CNZ. The turbidity removal decreased from $99.65 \%$ to 62.36 and from $99.91 \%$ to $73.24 \%$ over PAC and CNZ respectively. These results indicate that the adsorption of pollutants are dependent on the concentration as it provides the main driving force to overcome mass transfer limitations between the adsorbate and the adsorbent (Younis et al. 2015). At low concentrations, occupation of active binding sites involves adsorption, which is a fast process, while at higher concentrations, the active binding sites get saturated and further mass transfer from the liquid to solid phase takes place by valence forces through sharing, exchange of electrons and complex formation which is a relatively slow process ( Ho and McKay 1999).
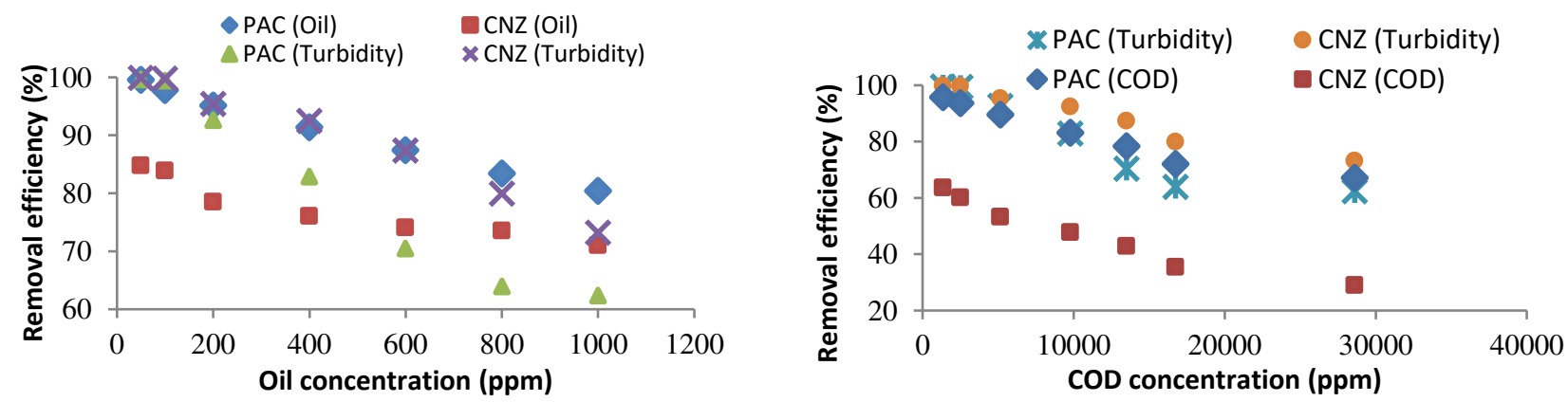

Fig. 5 (A) Effect of initial oil concentration on oil removal efficiency (B) Effect of initial COD concentration on oil COD removal efficiency $(\mathrm{pH}=2$, dose $=0.3 \mathrm{~g} / 100 \mathrm{~mL}$, time $=60 \mathrm{~min} \& 50 \mathrm{~min})$

One of the most important factors which could have a significant impact on the oil and COD removal and on decrease of turbidity from produced water is the temperature. Figure 6 show that the oil, COD and turbidity removal efficiency increased on increasing the temperature from 15 to $55^{\circ} \mathrm{C}$ at high oil and COD concentrations. The increase in the oil removal efficiency is due to the decrease in the oil viscosity. As the viscosity of the oil decreases, the oil uptake of the sorbent increases (Li. 2013). In addition, it is known that increasing the temperature the rate of diffusion of the adsorbate molecules increases across the external boundary layer and in the internal pores of the adsorbent particles, owing to the decrease in the viscosity of the solution. Thus, a change in temperature will change the equilibrium capacity of the adsorbent for a particular adsorbate (Ya-Li et al. 2008). However, at low concentration there was no change in the removal efficiency when the temperature increased because the effect of temperature at low concentration hardly can be observed. 

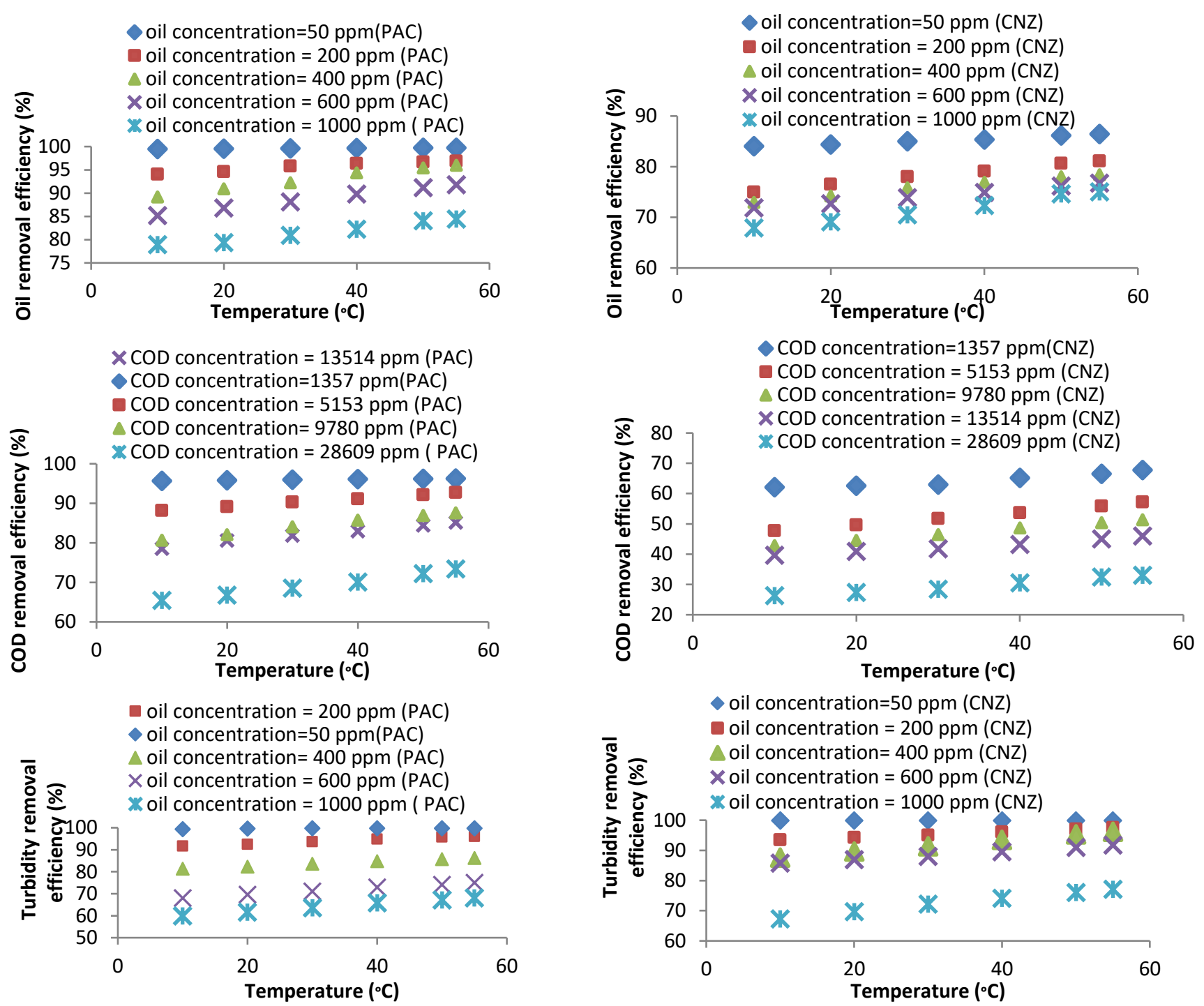

Fig. 5 (A) Effect of temperature on oil removal efficiency by PAC dose $=0.3 \mathrm{~g} / 100 \mathrm{~mL}(\mathbf{B}))$ Effect of temperature on oil removal efficiency by $\mathrm{CNZ}$ dose $=0.3 \mathrm{~g} / 100 \mathrm{~mL}(\mathbf{C})$ Effect of temperature on COD removal efficiency by PAC dose $=0.3 \mathrm{~g} / 100 \mathrm{~mL}(\mathbf{D}))$ Effect of temperature on COD removal efficiency by CNZ dose $=0.3 \mathrm{~g} / 100 \mathrm{~mL}(\mathbf{E})$ Effect of temperature on turbidity oil removal efficiency by PAC dose $=0.3 \mathrm{~g} / 100 \mathrm{~mL}(\mathrm{pH}=2$, time $=60 \mathrm{~min})(\mathbf{F}))$ Effect of temperature on turbidity removal efficiency by $\mathrm{CNZ} \mathrm{dose}=0.25 \mathrm{~g} / 100 \mathrm{~mL}(\mathrm{pH}=2$, time $=50 \mathrm{~min}$ )

\section{Adsorption isotherms models}

The adsorption isotherm provides a relation between the total mass of adsorbed adsorbate per unit mass of sorbent at constant ambient conditions. In order to develop adsorption isotherms, adsorption experiments were performed. In these experiments, the amount of adsorbent was kept constant while the initial concentration of the adsorbate was varied. Langmuir adsorption isotherm and Freundlich adsorption isotherm are the most common isotherms which are used for adsorption studies (Tchobanoglous et al. 2003). The equilibrium data were correlated using Langmuir Eq. (3), Freundlich Eq. (4), and Temkin Eq. (5) isotherms.

$$
\begin{aligned}
& \frac{\mathrm{C}_{\mathrm{eq}}}{\mathrm{q}_{\mathrm{e}}}=\frac{1}{\mathrm{q}_{\max }} \mathrm{C}_{\mathrm{eq}}+\frac{1}{\mathrm{~b} \mathrm{q}_{\max }} \\
& \ln \mathrm{q}_{\mathrm{e}}=\ln \mathrm{K}_{\mathrm{f}}+\frac{1}{n} \ln \mathrm{C}_{\mathrm{e}} \\
& \mathrm{q}_{\mathrm{e}}=\frac{\mathrm{RT}}{\mathrm{b}_{\mathrm{T}}} \ln \mathrm{A}_{\mathrm{T}}+\frac{\mathrm{RT}}{\mathrm{b}_{\mathrm{T}}} \ln \mathrm{C}_{\mathrm{e}}
\end{aligned}
$$


where: $\mathrm{q}_{\mathrm{e}}$ is the amount of the substance adsorbed at equilibrium per amount of adsorbent; $\mathrm{q}_{\max }$ is the saturation monolayer adsorption capacity, $\mathrm{C}_{\mathrm{eq}}$ is the equilibrium concentration, $\mathrm{b}$ is the Langmuir adsorption equilibrium constant, $\mathrm{K}_{\mathrm{f}}$ and $\mathrm{n}$ are the Freundlich constants, and $b_{\mathrm{T}}$ is the Temkin equilibrium adsorption constant.

The results obtained from the linear plots of Langmuir, Freundlich and Temkin models are represented in Table 3. A comparison between the correlation coefficients $\mathrm{R}^{2}$ obtained from Langmuir, Freundlich and Temkin models indicates that the experimental data fit well to the Freundlich model. In addition, $0<1 / \mathrm{n}<1$ indicates that the adsorption of oil and COD over the adsorbents is a favorable process. Similar results have been obtained by Abdelwahab et al. 2020

Table 3 Isotherm parameters for oil and COD adsorbed over PAC and CNZ with the correlation coefficient.

\begin{tabular}{|c|c|c|c|c|c|c|c|c|c|}
\hline \multirow[t]{2}{*}{ Isotherms } & \multicolumn{3}{|c|}{ Langmuir } & \multicolumn{3}{|c|}{ Freundlich } & \multicolumn{3}{|c|}{ Temkin } \\
\hline & $\begin{array}{c}\mathrm{q}_{\max } \\
(\mathrm{mg} / \mathrm{g})\end{array}$ & $\mathrm{K}_{\mathrm{L}}(\mathrm{L} / \mathrm{mg})$ & $\overline{\mathrm{R}^{2}}$ & $\begin{array}{l}\mathrm{K}_{\mathrm{F}}\left(\mathrm{mg}^{1-\mathrm{n}}\right. \\
\left.\mathrm{g}^{-1} \mathrm{~L}^{\mathrm{n}}\right)\end{array}$ & $1 / \mathrm{n}$ & $\overline{\mathrm{R}^{2}}$ & $\mathrm{~A}_{\mathrm{t}}(\mathrm{L} / \mathrm{g})$ & $\mathrm{b}_{\mathrm{t}}(\mathrm{J} / \mathrm{mol})$ & $\overline{\mathrm{R}^{2}}$ \\
\hline PAC (Oil) & 416 & 0.03709 & 0.9503 & 0.26859 & 0.4199 & 0.9901 & 0.52123 & 45.43919 & 0.9672 \\
\hline CNZ (Oil) & 526 & 0.00366 & 0.8834 & 0.76952 & 0.7701 & 0.9983 & 0.10106 & 34.94065 & 0.8882 \\
\hline PAC (COD) & 10000 & 0.00053 & 0.9142 & 0.22407 & 0.5134 & 0.9967 & 0.01400 & 1.56858 & 0.8843 \\
\hline CNZ (COD) & 5000 & 0.00013 & 0.9805 & 0.46283 & 0.6128 & 0.9825 & 0.00231 & 3.136802 & 0.9645 \\
\hline
\end{tabular}

\section{Adsorption thermodynamics}

It can clearly be noticed from Figure 6 that the oil and COD adsorption capacities of PAC and CNZ increased by increasing the adsorption temperature, demonstrating the endothermic nature of the adsorption process, which is further demonstrated by the calculated positive value of $\Delta \mathrm{H}_{0}$. As shown in Table 4, the positive value of $\Delta \mathrm{S}_{\mathrm{o}}$ indicates the reversible characteristic of the adsorption of oil and COD over PAC and CNZ. $\Delta \mathrm{G}_{\mathrm{o}}$ values were positive indicating that the adsorption process led to an increase in Gibbs free energy. Positive $\Delta \mathrm{G}_{\mathrm{o}}$ values of oil and COD over CNZ indicate the non-spontaneity of the adsorption process and the negative $\Delta \mathrm{G}_{\mathrm{o}}$ value of oil and COD over PAC indicates the adsorption process was spontaneous.
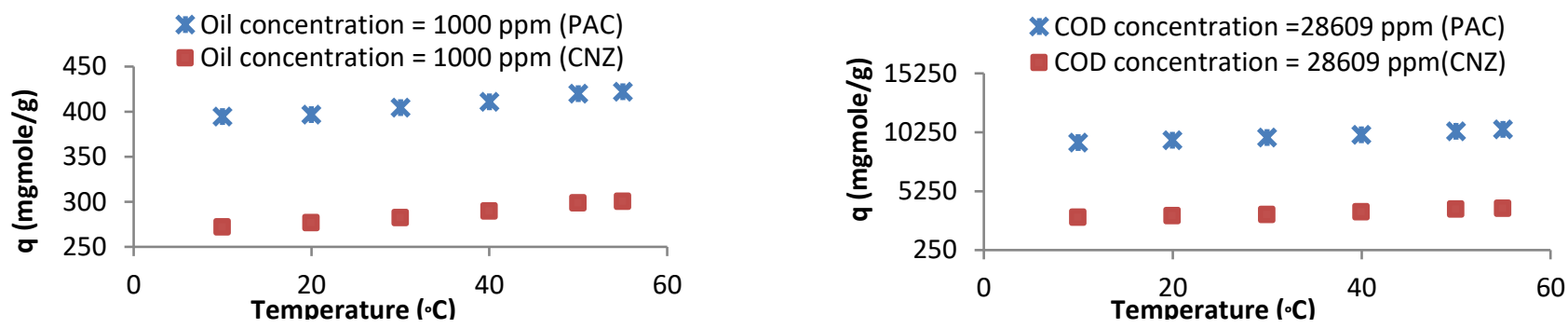

Fig. 6 (A) The variations of adsorption capacity of oil as a function of temperature (B) The variations of adsorption capacity of COD as a function of temperature

Table 4. Thermodynamic parameters for the adsorption of oil and COD over PAC and CNZ adsorbents

\begin{tabular}{|c|c|c|c|c|c|c|c|c|c|c|c|c|}
\hline \multirow[b]{2}{*}{$\begin{array}{l}\text { Temp. } \\
\left({ }^{\circ} \mathrm{C}\right)\end{array}$} & \multicolumn{3}{|c|}{ Oil adsorbed by PAC } & \multicolumn{3}{|c|}{ Oil adsorbed by CNZ } & \multicolumn{3}{|c|}{ COD adsorbed by PAC } & \multicolumn{3}{|c|}{ COD adsorbed by CNZ } \\
\hline & $\begin{array}{c}\Delta \mathrm{H}^{\mathrm{o}} \\
(\mathrm{KJ} / \mathrm{mol})\end{array}$ & $\begin{array}{c}\Delta \mathrm{S}^{\circ} \\
\left(\mathrm{KJ} / \mathrm{mol} \cdot{ }^{\circ} \mathrm{C}\right)\end{array}$ & $\begin{array}{c}\Delta \mathrm{G}^{\mathrm{o}} \\
(\mathrm{KJ} / \mathrm{mol})\end{array}$ & $\begin{array}{c}\Delta \mathrm{H}^{\circ} \\
(\mathrm{KJ} / \mathrm{mol})\end{array}$ & $\begin{array}{c}\Delta \mathrm{S}^{\circ} \\
\left(\mathrm{KJ} / \mathrm{mol} \cdot{ }^{\circ} \mathrm{C}\right)\end{array}$ & $\begin{array}{c}\Delta \mathrm{G}^{\mathrm{o}} \\
(\mathrm{KJ} / \mathrm{mol})\end{array}$ & $\begin{array}{c}\Delta \mathrm{H}^{\mathrm{o}} \\
(\mathrm{KJ} / \mathrm{mol})\end{array}$ & $\begin{array}{c}\Delta \mathrm{S}^{\circ} \\
\left(\mathrm{KJ} / \mathrm{mol} \cdot{ }^{\circ} \mathrm{C}\right)\end{array}$ & $\begin{array}{c}\Delta \mathrm{G}^{\mathrm{o}} \\
(\mathrm{KJ} / \mathrm{mol})\end{array}$ & $\begin{array}{c}\Delta \mathrm{H}^{\mathrm{o}} \\
(\mathrm{KJ} / \mathrm{mol})\end{array}$ & $\begin{array}{c}\Delta \mathrm{S}^{\circ} \\
\left(\mathrm{KJ} / \mathrm{mol} \cdot{ }^{\circ} \mathrm{C}\right)\end{array}$ & $\begin{array}{c}\Delta \mathrm{G}^{\mathrm{o}} \\
(\mathrm{KJ} / \mathrm{mol})\end{array}$ \\
\hline 10 & & & -1473 & & & 389 & & & -107 & & & 4573 \\
\hline 30 & 6758 & 28 & -1888 & & & 111 & & & -213 & & & 4633 \\
\hline 40 & & & -2175 & 6278 & 20 & 93 & 6440 & 22 & -415 & 5762 & 4 & 4528 \\
\hline 50 & & & -2589 & & & 65 & & & -709 & & & 4433 \\
\hline
\end{tabular}

\section{Analysis of adsorption kinetics}

The kinetics of oil and COD adsorption over PAC and CNZ were studied at $25^{\circ} \mathrm{C}$. The data were fitted to both pseudo-firstorder and pseudo-second-order kinetics models (Febrianto et al. 2009). The linear forms of the equations are given by Eqs. (6) and (7). 
$\ln \left(\mathrm{q}_{\mathrm{e}}-\mathrm{q}_{\mathrm{t}}\right)=\ln \mathrm{q}_{\mathrm{e}}-\mathrm{k}_{1} \mathrm{t}$

$\frac{\mathrm{t}}{\mathrm{q}_{\mathrm{t}}}=\frac{1}{\mathrm{k}_{2} \mathrm{q}_{\mathrm{e}}^{2}}+\frac{\mathrm{t}}{\mathrm{q}_{\mathrm{e}}}$

where: qt $(\mathrm{mg} / \mathrm{g})$ is the amount of oil adsorbed at a given time and qe $(\mathrm{mg} / \mathrm{g})$ is the amount of oil and COD adsorbed at equilibrium, $\mathrm{k}_{1}$ is pseudo-first-order rate constant $(1 / \mathrm{min})$, and $\mathrm{k}_{2}$ is the pseudo-second-order rate constant ( $\left.\mathrm{g} / \mathrm{mg} \mathrm{min}\right)$.

Table 5 lists the pseudo-first and pseudo-second order kinetic models parameters values from them plots Figure 8 reveal that the latter model fits the data well as compared to the former model. The $\mathrm{R}^{2}$ value for the pseudo-second-order kinetic model was higher than that of pseudo-first-order kinetic model.

Table 5 Kinetic adsorption parameters obtained using pseudo-first-order and pseudo-second-order models

\begin{tabular}{lcccccc}
\hline \multirow{3}{*}{ Adsorbent } & \multicolumn{3}{c}{ pseudo-first-order } & \multicolumn{3}{c}{ pseudo-second-order } \\
\cline { 2 - 7 } & $\begin{array}{c}\mathrm{q}_{\mathrm{e}} \\
\left(\mathrm{mg} \mathrm{g}^{-1}\right)\end{array}$ & $\begin{array}{c}\mathrm{k}_{1} \\
\left(\mathrm{~min}^{-1}\right)\end{array}$ & $\mathrm{R}^{2}$ & $\begin{array}{c}\mathrm{q}_{\mathrm{e}} \\
\left(\mathrm{mg} \mathrm{g}^{-1}\right)\end{array}$ & $\begin{array}{c}\mathrm{k}_{2} \\
\left(\mathrm{~g} \mathrm{~min}^{-1} \mathrm{mg}^{-1}\right)\end{array}$ & $\mathrm{R}^{2}$ \\
nyyyyyy PAC (Oil) & 7.8146 & 0.0534 & 0.8913 & 50.34 & 0.004819 & 0.9995 \\
CNZ (Oil) & 3.7946 & 0.0544 & 08779 & 32.15 & 0.013359 & 0.9995 \\
PAC (COD) & 24.230 & 0.0446 & 0.8735 & 1111.11 & 0.000218 & 0.9991 \\
CNZ (COD) & 11.738 & 0.0415 & 0.8533 & 555.55 & 0.000456 & 0.9982 \\
\hline
\end{tabular}

\section{The best operational conditions of adsorption for removal oil, turbidity, chemical oxygen demand (COD) and total petroleum hydrocarbon (TPH)}

On the basis of data summarized in Tables 6 and 7 it can be seen that good results were achieved for treatment of PW by monitoring the turbidity, oil, TPH and COD removal efficiencies by using natural and synthetic adsorbents. Tables 6 and 7 show the maximum removal efficiency of oil, COD and TPH by using PAC. At the same time both types of zeolites exhibited high decrease in turbidity. Furthermore, the zeolites were less effective than PAC for removal of organic pollutants by batch adsorption. The lowest COD removal efficiency was observed over CNZ. Also the concentration of pollutants was within the regulatory limit by using PAC adsorbent. This may be attributed to the difference in the surface areas of the adsorbents. PAC has a larger surface area than the CNZ.

Table 6 The Optimum condition on the turbidity removal efficiency (initial turbidity $=435$ NTU)

\begin{tabular}{cccccc}
\hline Type of adsorbent & Dose $(\mathrm{g} / 100 \mathrm{~mL})$ & $\mathrm{pH}$ & Time $(\mathrm{min})$ & Res.T(NTU) & $\mathrm{R}_{\mathrm{eT}} \%$ \\
\hline PAC & 0.3 & 2 & 60 & 1.5 & 99.65 \\
CNZ & 0.3 & 2 & 60 & 0.38 & 99.91 \\
XSZ & 0.3 & 2 & 60 & 0.13 & 99.97 \\
\hline
\end{tabular}

Res.т: Residual turbidity, $\mathrm{ReT}_{\mathrm{e}}$ : Removal of turbidity

Table 7 The Optimum condition on the oil and COD removal efficiency (optimum $\mathrm{C}_{\text {oil }}=50 \mathrm{ppm}$ and $\mathrm{C}_{\mathrm{COD}}=1357 \mathrm{ppm}$ )

\begin{tabular}{ccccccc}
\hline Type of adsorbent & Dose $(\mathrm{g} / 100 \mathrm{~mL})$ & $\mathrm{pH}$ & Time $(\mathrm{min})$ & $\mathrm{Re}_{\text {oil }} \%$ & $\operatorname{Re}_{\mathrm{COD}} \%$ & $\operatorname{Re}_{\mathrm{TPH}} \%$ \\
\hline PAC & 0.3 & 2 & 60 & 99.58 & 95.87 & 99.84 \\
CNZ & 0.3 & 2 & 50 & 84.8 & 63.74 & 85.06 \\
XSZ & 0.3 & 2 & 50 & 91.08 & 80.32 & 93.59 \\
\hline
\end{tabular}

$\mathrm{Re}_{\text {oil }}$ : Removal of oil, RecoD : Removal of COD, ReTPH :Removal of total petroleum hydrocarbon

\section{Desorption studies}

The desorption step is considered as one of the most important features of the adsorption process, which decreases the process cost. Therefore adsorbent reuse experiments were carried out. Electric thermal treatment of the used $\mathrm{CNZ}$ and XSZ at $700{ }^{0} \mathrm{C}$ and chemical treatment of PAC were applied after each run and then those were reused in the next run under the same conditions. The results obtained with regenerated and recycled adsorbents are shown in Table 8. This means that adsorbents can be regenerated and reused efficiently. 
Table 8 Results obtained after adsorbent regeneration

\begin{tabular}{ccccc}
\hline Type of adsorbent & $\operatorname{Re}_{\mathrm{T}} \%$ & $\mathrm{Re}_{\text {oil }} \%$ & $\mathrm{ReCOD} \%$ & $\operatorname{Re}_{\mathrm{TPH}} \%$ \\
\hline PAC & 99.71 & 89.8 & 87.1 & 90.54 \\
CNZ & 99.59 & 81 & 61.82 & 81.70 \\
XSZ & 99.75 & 83.2 & 71.48 & 84.45 \\
\hline
\end{tabular}

\section{Conclusions}

Batch adsorption experiments for the adsorption of oil, chemical oxygen demand (COD), turbidity from produced water (PW) have been carried out by using powdered activated carbon (PAC) and clinoptilolite natural zeolite (CNZ) adsorbents. Batch experiment showed that the oil, COD and turbidity removal efficiencies increase on increasing the contact time, adsorbents dosage, and temperature, and decreases with increase in $\mathrm{pH}$ and initial oil and COD concentrations. The adsorption isotherms studies showed that the adsorption processes can be well fitted by the Freundlich isotherm model with a high correlation. Also the adsorption kinetics of oil and COD over PAC and CNZ can be well described by a pseudo-second order kinetic model.

At optimum parameters in adsorption process the best removal efficiencies of oil, COD, TPH and turbidity were 99.58\%, 95.87\%, 99.84\% and 99.65\%)over PAC. In case of CNZ those were $84.8 \%, 63.74 \%, 85.06 \%$ and $99.91 \%$ and in case of XSZ the values were to $91.08 \%, 80.32 \%, 93.57 \%$ and $99.97 \%$, respectively. The results show that PAC can be used with higher effectiveness for oil, COD and TPH removal from POW but XSZ exhibited the best efficiency in turbidity reduction. PAC, $\mathrm{CNZ}$ and XSZ can be well regenerated and can be effectively reused for the treatment of PW. For commercialization of the experimental results scale-up and pilot plant experiments have to be carried out in order to provide full picture on the feasibility of the industrial applications.

Conflicts of Interest: All authors, including Eman Hashim Khader, Thamer Jassim Mohammed, Nourollah Mirghaffari, Ali Dawood Salman, Juzsakova Tatjána, Abdullah Adnan Thamer, state that they do not have a conflict of interest.

\section{Acknowledgments}

The authors would like to say thanks to the staff of Petroleum Research and Development Center of Oil Ministry of Iraq and the staff of University of Isfahan for their support during conducting this work.

\section{References}

Abdelwahab, N. A., Shukry, N., \& El-kalyoubi, S. F. (2020). Separation of emulsified oil from wastewater using polystyrene and surfactant modified sugarcane bagasse wastes blend. Clean Technologies and Environmental Policy, 1-15.

Al-Ghouti, M. A., Al-Kaabi, M. A., Ashfaq, M. Y., \& Da'na, D. A. (2019). Produced water characteristics, treatment and reuse: A review. Journal of Water Process Engineering, 28, 222-239.

Al-Haddad, A., Chmielewska, E., \& Al-Radwan, S. (2007). A brief comparable lab. examination for oil refinery wastewater treatment using the zeolitic and carbonaceous adsorbents. Petroleum \& Coal, 49(1), 21-26.

Babel, S., \& Kurniawan, T. A. (2003). Low-cost adsorbents for heavy metals uptake from contaminated water: a review. Journal of hazardous materials, 97(1-3), 219-243.

Bailey, S. E., Olin, T. J., Bricka, R. M., \& Adrian, D. D. (1999). A review of potentially low-cost sorbents for heavy metals. Water research, 33(11), 2469-2479.

Bandura, L., Panek, R., Rotko, M., \& Franus, W. (2016). Synthetic zeolites from fly ash for an effective trapping of BTX in gas stream. Microporous and Mesoporous Materials, 223, 1-9.

Bandura, L., Woszuk, A., Kołodyńska, D., \& Franus, W. (2017). Application of mineral sorbents for removal of petroleum substances: a review. Minerals, 7(3), 37.

Bansal, R. C., \& Goyal, M. (2005). Activated carbon adsorption. CRC press.

Chiou, M. S., \& Li, H. Y. (2003). Adsorption behavior of reactive dye in aqueous solution on chemical cross-linked chitosan beads. Chemosphere, 50(8), 1095-1105.

Daoud, W. Y. (2020). Using Zeolite and Granule Activated Carbon Combination for Remediating Landfill Leachatecontaminated Groundwater in Permeable Reactive Barriers. Syrian Journal of Agricultural Research, 7(6), 183-191.

Desta, M. B. (2013). Batch sorption experiments: Langmuir and Freundlich isotherm studies for the adsorption of textile metal ions onto teff straw (Eragrostis tef) agricultural waste. Journal of thermodynamics, 2013.

El-Naas, M. H., Al-Zuhair, S., \& Alhaija, M. A. (2010). Reduction of COD in refinery wastewater through adsorption on datepit activated carbon. Journal of hazardous materials, 173(1-3), 750-757.

Fakhru'l-Razi, A., Pendashteh, A., Abdullah, L. C., Biak, D. R. A., Madaeni, S. S., \& Abidin, Z. Z. (2009). Review of 
technologies for oil and gas produced water treatment. Journal of hazardous materials, 170(2-3), 530-551.

Febrianto, J., Kosasih, A. N., Sunarso, J., Ju, Y. H., Indraswati, N., \& Ismadji, S. (2009). Equilibrium and kinetic studies in adsorption of heavy metals using biosorbent: a summary of recent studies. Journal of hazardous materials, 162(2-3), 616645.

Geankoplis, C. J. (2003). Transport processes and separation process principles:(includes unit operations). Prentice Hall Professional Technical Reference.

Gupta, V. K., Mittal, A., Jhare, D., \& Mittal, J. (2012). Batch and bulk removal of hazardous colouring agent Rose Bengal by adsorption techniques using bottom ash as adsorbent. RSC advances, 2(22), 8381-8389.

Hamidpour, M., Kalbasi, M., Afyuni, M., Shariatmadari, H., Holm, P. E., \& Hansen, H. C. B. (2010). Sorption hysteresis of $\mathrm{Cd}$ (II) and $\mathrm{Pb}$ (II) on natural zeolite and bentonite. Journal of hazardous materials, 181(1-3), 686-691.

Han, R., Wang, Y., Zou, W., Wang, Y., \& Shi, J. (2007). Comparison of linear and nonlinear analysis in estimating the Thomas model parameters for methylene blue adsorption onto natural zeolite in fixed-bed column. Journal of Hazardous Materials, 145(1-2), 331-335.

Hedar, Y. (2018). Pollution Impact and Alternative Treatment for Produced Water. In E3S Web of Conferences (Vol. 31, p. 03004). EDP Sciences.

Ho, Y. S., \& McKay, G. (1999). Pseudo-second order model for sorption processes. Process biochemistry, 34(5), 451-465.

Ibrahim, S., Ang, H. M., \& Wang, S. (2009). Removal of emulsified food and mineral oils from wastewater using surfactant modified barley straw. Bioresource technology, 100(23), 5744-5749.

Igunnu, E. T., \& Chen, G. Z. (2014). Produced water treatment technologies. International Journal of Low-Carbon Technologies, 9(3), 157-177.

Jhadhav, S. (2015). Value Added Products from Gasification-Activated Carbon. The Combustion, Gasification and Propulsion Laboratory (CGPL) at the Indian Institute of Science (IISc). Retrieved, 30.

Kim, S., Cho, C. W., Song, M. H., Bediako, J. K., Yun, Y. S., \& Choi, Y. E. (2018). Potentiometric titration data on the enhancement of sorption capacity of surface-modified biosorbents: functional groups scanning method. Clean Technologies and Environmental Policy, 20(10), 2191-2199.

Li, J., Luo, M., Zhao, C. J., Li, C. Y., Wang, W., Zu, Y. G., \& Fu, Y. J. (2013). Oil removal from water with yellow horn shell residues treated by ionic liquid. Bioresource technology, 128, 673-678.Ya-Li, S., Ji-Tai, L. and Hua, C. (2008). Removal of acid brown 348 dye from aqueous solution by ultrasound irradiated exfoliated graphite. Indian Journal of Chemical Technology, 15, pp. 443-448.

Malekmohammadi, S., Mirbagheri, A., \& Ehteshami, M. (2016). Comparison of silica, activated carbon, and zeolite adsorbents in the removal of ammonium, iron, COD, turbidity and phosphate pollutants, and investigating the effect of discharge on the removal of pollutants. International Journal of Humanities and Cultural Studies, 3(2), 667-679.

Malik, P. K. (2004). Dye removal from wastewater using activated carbon developed from sawdust: adsorption equilibrium and kinetics. Journal of Hazardous Materials, 113(1-3), 81-88.

McCormack, P., Jones, P., Hetheridge, M. J., \& Rowland, S. J. (2001). Analysis of oilfield produced waters and production chemicals by electrospray ionisation multi-stage mass spectrometry (ESI-MSn). Water research, 35(15), 3567-3578.

Mohan, S., \& Gandhimathi, R. (2009). Removal of heavy metal ions from municipal solid waste leachate using coal fly ash as an adsorbent. Journal of hazardous materials, 169(1-3), 351-359.

Nekoo, S. H., \& Fatemi, S. (2013). Experimental study and adsorption modeling of COD reduction by activated carbon for wastewater treatment of oil refinery. Iranian Journal of Chemistry and Chemical Engineering (IJCCE), 32(3), 81-89.

Paliulis, D. (2016). Removal of Formaldehyde from Synthetic Wastewater Using Natural and Modified Zeolites. Polish Journal of Environmental Studies, 25(1).

Pandey, S., Fosso-Kankeu, E., Spiro, M. J., Waanders, F., Kumar, N., Ray, S. S., ... \& Kang, M. (2020). Equilibrium, kinetic, and thermodynamic studies of lead ion adsorption from mine wastewater onto MoS2-clinoptilolite composite. Materials Today Chemistry, 18, 100376.

Pandey, S., Fosso-Kankeu, E., Spiro, M. J., Waanders, F., Kumar, N., Ray, S. S., ... \& Kang, M. (2020). Equilibrium, kinetic, and thermodynamic studies of lead ion adsorption from mine wastewater onto MoS2-clinoptilolite composite. Materials Today Chemistry, 18, 100376.

Payne, K. B., \& Abdel-Fattah, T. M. (2004). Adsorption of divalent lead ions by zeolites and activated carbon: effects of $\mathrm{pH}$, temperature, and ionic strength. Journal of Environmental Science and Health, Part A, 39(9), 2275-2291.

Pirilä, M. (2015). Adsorption and photocatalysis in water treatment: active, abundant and inexpensive materials and methods. Acta Universitatis Ouluensis, University Of Oulu, Oulu.

Rashed, M. N. (2013). Adsorption technique for the removal of organic pollutants from water and wastewater. Organic pollutants-monitoring, risk and treatment, 7, 167-194.

Sen, T. (2015). Physical chemical and biological treatment processes for water and wastewater (pp. 9-11). Nova Science Publishers.

Show, P. L., Thangalazhy-Gopakumar, S., \& Foo, D. C. (2021) Sustainable technologies for waste reduction and pollutants removals. Clean Technologies and Environmental Policy, 1-2. 
Tchobanoglous, G., Burton, F. L., \& Stensel, H. D. (2003). Wastewater engineering: treatment and reuse, 4th edn. Metcalf \& Eddy Inc.

Vega, D. P., González, C., Escalante, C. A., Gallego, J., Salamanca, M., \& Manrique-Losada, L. (2018). Use of faujasite-type zeolite for ion adsorption in municipal wastewater. Tecnología y ciencias del agua, 9(4), 184-208.

Wdowin, M., Franus, M., Panek, R., Badura, L., \& Franus, W. (2014). The conversion technology of fly ash into zeolites. Clean Technologies and Environmental Policy, 16(6), 1217-1223.

Yang, X., Yang, S., Yang, S., Hu, J., Tan, X., \& Wang, X. (2011). Effect of pH, ionic strength and temperature on sorption of $\mathrm{Pb}$ (II) on NKF-6 zeolite studied by batch technique. Chemical Engineering Journal, 168(1), 86-93.

Younis, S. A., El-Gendy, N. S., El-Azab, W. I., \& Moustafa, Y. M. (2015). Kinetic, isotherm, and thermodynamic studies of polycyclic aromatic hydrocarbons biosorption from petroleum refinery wastewater using spent waste biomass. Desalination and water treatment, 56(11), 3013-3023.

Zhao, S. (2015). Enhanced Physicochemical Processes for the Treatment of Petroleum-Contaminated Systems (Doctoral dissertation, Faculty of Graduate Studies and Research, University of Regina).

Khader, E.H., Mohammed, T.H.J. and Mirghaffari, N., 2018. Use of natural coagulants for removal of COD, oil and turbidity from produced waters in the petroleum industry. J. Petrol. Environ. Biotechno, 9, p.374.

Albayati, T. M., Sabri, A. A., \& Abed, D. B. (2020). Functionalized SBA-15 by amine group for removal of Ni (II) heavy metal ion in the batch adsorption system. DESALINATION AND WATER TREATMENT, 174, 301-310.

Nidheesh, P. V., Kumar, A., Babu, D. S., Scaria, J., \& Kumar, M. S. (2020). Treatment of mixed industrial wastewater by electrocoagulation and indirect electrochemical oxidation. Chemosphere, 251, 126437.

Zhu, G., Fang, H., Xiao, Y., \& Hursthouse, A. S. (2020). The application of fluorescence spectroscopy for the investigation of dye degradation by chemical oxidation. Journal of Fluorescence, 30(5), 1271-1279.

Guo, D., Wang, H., Fu, P., Huang, Y., Liu, Y., Lv, W., \& Wang, F. (2018). Diatomite precoat filtration for wastewater treatment: Filtration performance and pollution mechanisms. Chemical Engineering Research and Design, 137, 403-411.

Quintana, J. B., Weiss, S., \& Reemtsma, T. (2005). Pathways and metabolites of microbial degradation of selected acidic pharmaceutical and their occurrence in municipal wastewater treated by a membrane bioreactor. Water research, 39(12), 2654-2664.

Xiao, Y., Xu, S., Li, Z., An, X., Zhou, L., Zhang, Y., \& Shiang, F. Q. (2010). Progress of applied research on TiO 2 photocatalysis-membrane separation coupling technology in water and wastewater treatments. Chinese science bulletin, 55(14), 1345-1353.

Alardhi, S. M., Albayati, T. M., \& Alrubaye, J. M. (2020). Adsorption of the methyl green dye pollutant from aqueous solution using mesoporous materials MCM-41 in a fixed-bed column. Heliyon, 6(1), e03253. 


\section{Figures}

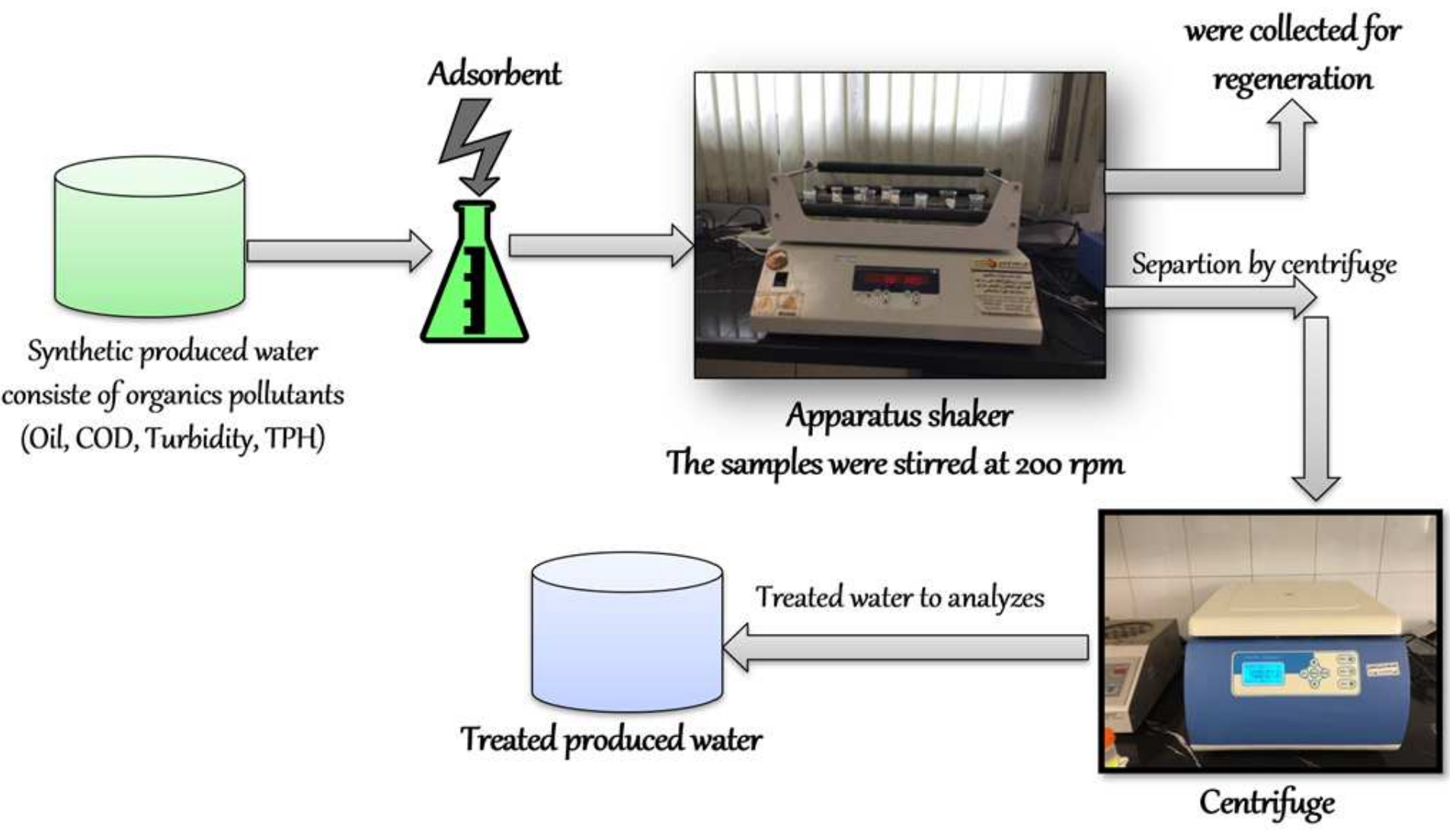

Figure 1

schematic view of an experimental apparatus
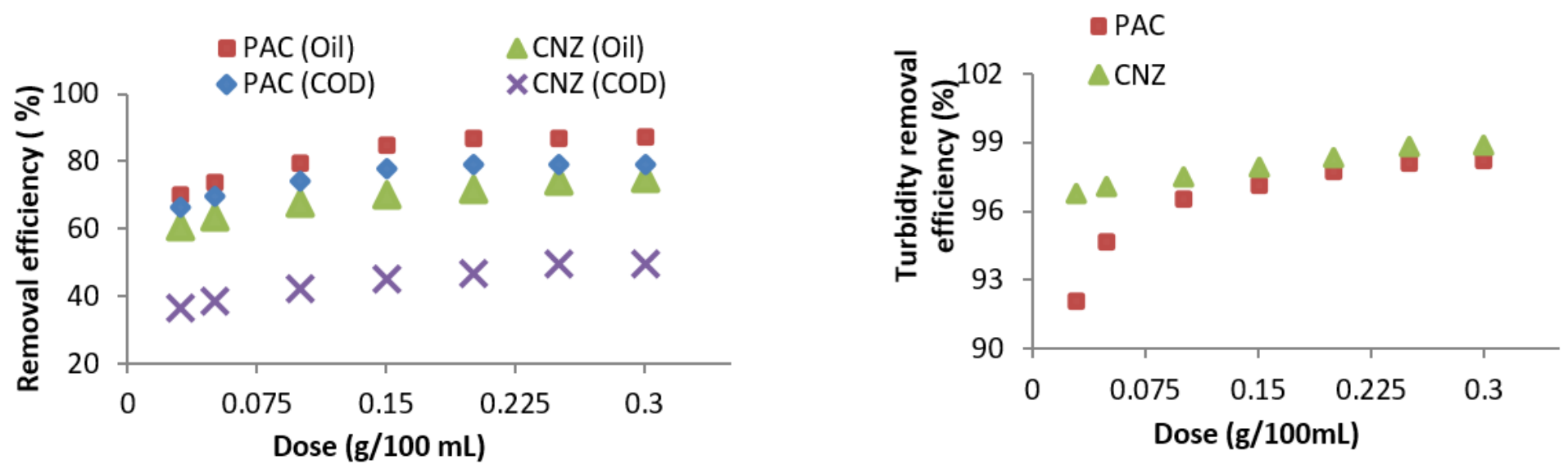

Figure 2

(A) Effect of adsorbent dose on oil and COD removal efficiency (Co Oil= $100 \mathrm{ppm}$, Co COD=2508 ppm, pH $=7$, time $=30 \mathrm{~min}$ ) (B) Effect of adsorbent dose on the removal efficiency of turbidity (Cinitial turbidity= $435 \mathrm{NTU}, \mathrm{pH}=7$, time $=30 \mathrm{~min}$ ) 

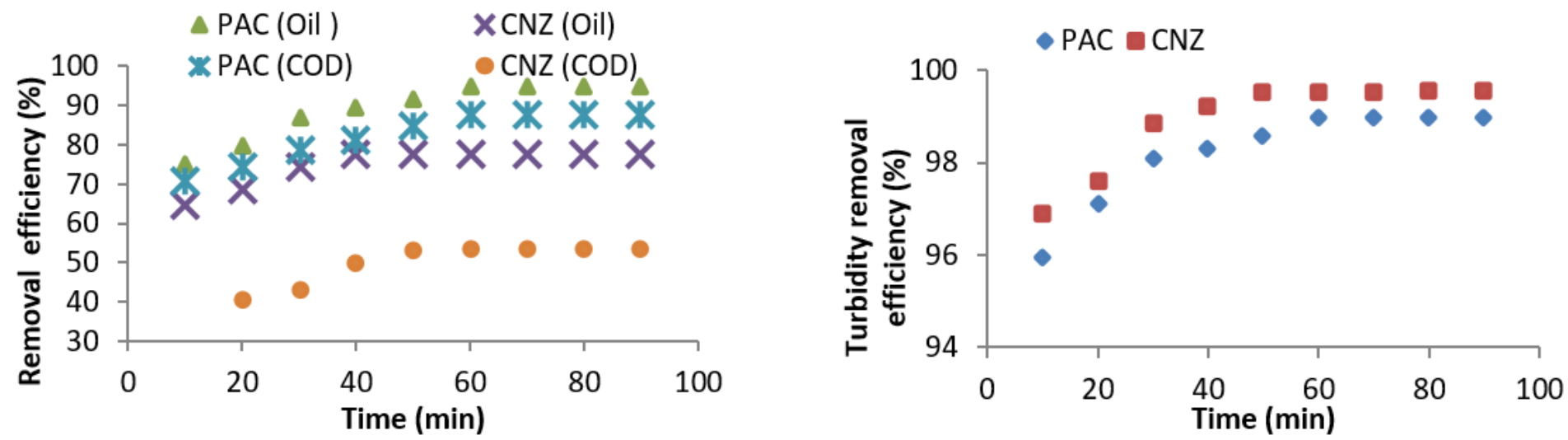

Figure 3

(A) Effect of contact time on oil and COD removal efficiency (Co Oil $=100 \mathrm{ppm}, \mathrm{Co}$ COD=2508 ppm, pH =7, dose $=0.3 \mathrm{~g} / 100 \mathrm{~mL}$ ) (B) Effect of adsorbent dose on the removal efficiency of turbidity (Cinitial turbidity= $435 \mathrm{NTU}, \mathrm{pH}=7$, dose $=0.3 \mathrm{~g} / 100 \mathrm{~mL}$ )
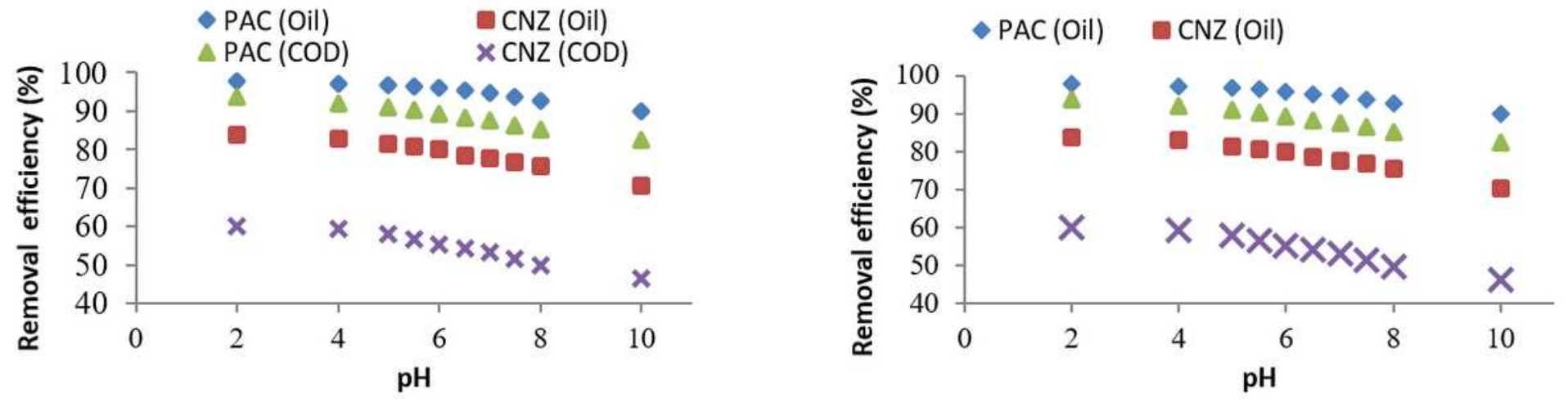

\section{Figure 4}

(A) Effect of contact time on oil and COD removal efficiency (Co Oil= 100 ppm, Co COD $=2508$ ppm, pH =7, dose $=0.3 \mathrm{~g} / 100 \mathrm{~mL}$, time $=60 \mathrm{~min} \& 50 \mathrm{~min}$ ) (B) Effect of adsorbent dose on the removal efficiency of turbidity (Cinitial turbidity $=435 \mathrm{NTU}, \mathrm{pH}=7$, dose $=0.3 \mathrm{~g} / 100 \mathrm{~mL}$, time $=60 \mathrm{~min}$ )
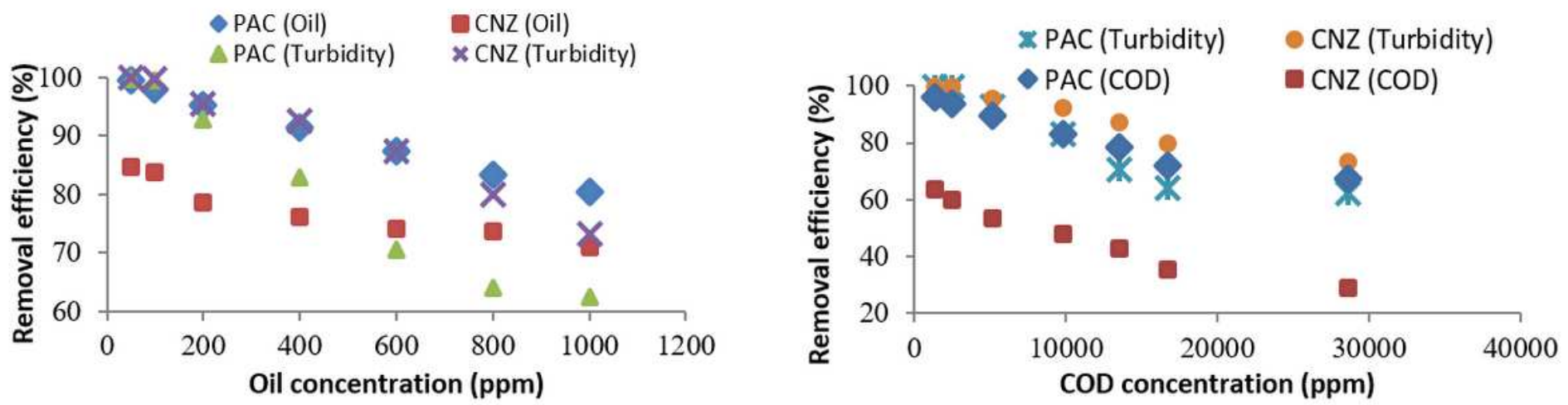


\section{Figure 5}

(A) Effect of initial oil concentration on oil removal efficiency (B) Effect of initial COD concentration on oil COD removal efficiency $(\mathrm{pH}=2$, dose $=0.3 \mathrm{~g} / 100 \mathrm{~mL}$, time $=60 \mathrm{~min} \& 50 \mathrm{~min}$ )
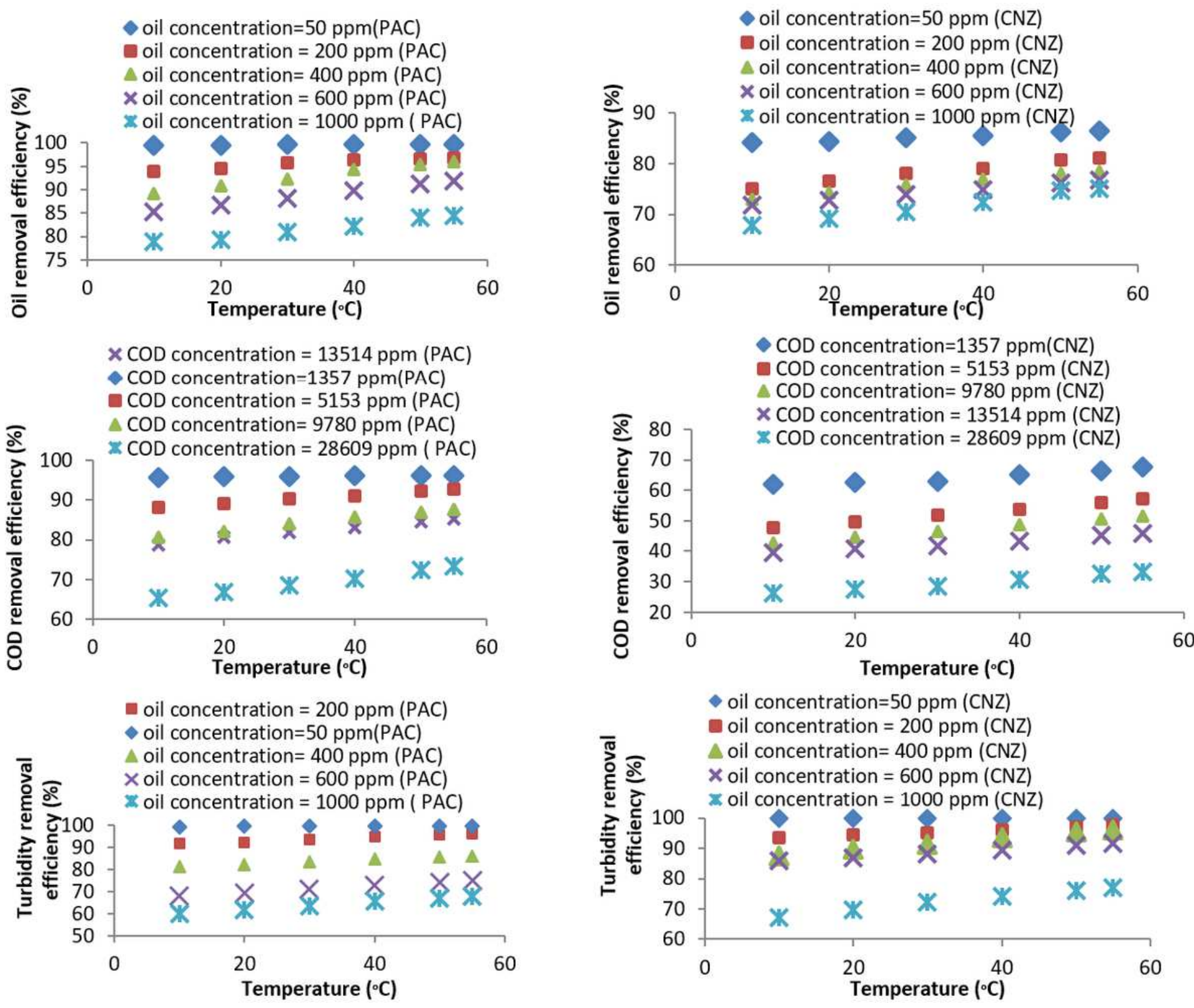

\section{Figure 6}

(A) Effect of temperature on oil removal efficiency by PAC dose $=0.3 \mathrm{~g} / 100 \mathrm{~mL}$ (B) ) Effect of temperature on oil removal efficiency by CNZ dose $=0.3 \mathrm{~g} / 100 \mathrm{~mL}(\mathrm{C})$ Effect of temperature on COD removal efficiency by PAC dose $=0.3 \mathrm{~g} / 100 \mathrm{~mL}$ (D) ) Effect of temperature on COD removal efficiency by CNZ dose $=0.3 \mathrm{~g} / 100 \mathrm{~mL}(\mathrm{E})$ Effect of temperature on turbidity oil removal efficiency by PAC dose $=0.3 \mathrm{~g} / 100 \mathrm{~mL}$ $(\mathrm{pH}=2$, time $=60 \mathrm{~min})(\mathrm{F}))$ Effect of temperature on turbidity removal efficiency by CNZ dose $=0.25 \mathrm{~g} / 100$ $\mathrm{mL}(\mathrm{pH}=2$, time $=50 \mathrm{~min})$ 

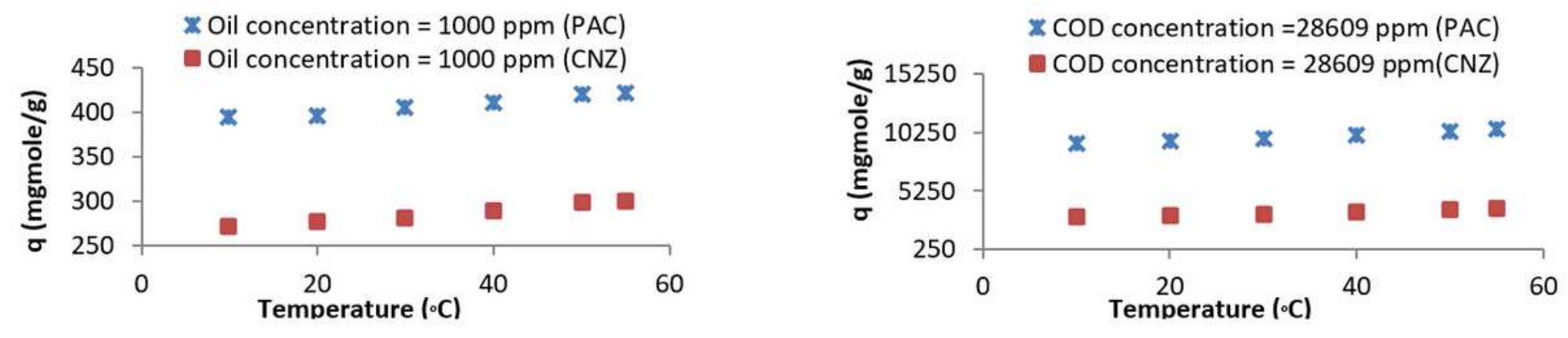

Figure 7

(A) The variations of adsorption capacity of oil as a function of temperature (B) The variations of adsorption capacity of COD as a function of temperature

\section{Supplementary Files}

This is a list of supplementary files associated with this preprint. Click to download.

- GraphicalAbstract.png 